\title{
UM ESTUDO SOBRE O TERMO rûạ̣ NA BÍBLIA HEBRAICA
}

\section{A STUDY ABOUT THE TERM rûah IN THE HEBREW BIBLE}

\author{
Manu Marcus Hubner*
}

Resumo: O termo rûạ̣ está repleto de significados na Bíblia Hebraica. Esse artigo é um estudo sintético das ocorrências e dos possíveis significados deste termo.

Palavras-chave: Bíblia Hebraica. rûaḥ. Espírito. Alma. Vento.

Abstract: The term rûah is full of meanings in the Hebrew Bible. This article is a synthetic study of the occurrences and possible meanings of this word.

Keywords: Hebrew Bible. rûah. Spirit. Soul. Wind.

O termo rûah está presente por volta de quatrocentas vezes na Bíblia Hebraica ${ }^{1}$. O livro no qual há o maior número de ocorrências, no total de $52^{2}$, é Ezequiel, famoso por suas visões proféticas no período do exílio babilônico ${ }^{3}$.

"Eis que farei entrar o espírito em vós, e vivereis; Porei tendões sobre vós, farei crescer carne sobre vós, sobre vós estenderei pele e porei em vós o espírito, e vivereis. [...] Olhei, e eis que havia tendões sobre eles, e cresceram as carnes, e se estendeu a pele sobre eles; mas não havia neles o espírito; [...] Vem dos quatro ventos, ó espírito, e assopra sobre estes mortos, para que vivam. Profetizei como ele me ordenara, e o espírito entrou neles, e viveram e se puseram em pé, um exército sobremodo numeroso" (Ez 37:5-10).

\footnotetext{
* Doutor em Letras pela Universidade de São Paulo.

Email: <marcushubner@gmail.com>.

${ }^{1}$ A Bíblia Hebraica, ou Tanach, é composta pelos 24 livros do Pentateuco, Profetas e Escritos. A Torá é o conjunto de livros que forma o Pentateuco. A palavra Torá é traduzida como “ensinamento, lei” por Jastrow (1903, p. 1657).

As abreviações dos livros da Bíblia seguem o padrão da Bíblia de Jerusalém. A Bíblia utilizada para citações do Pentateuco neste trabalho será a A Bíblia Sagrada. Trad. João Ferreira de Almeida, edição revista e atualizada do software Bible Works.

${ }^{2}$ Frahm (2013, p. 112).

${ }^{3} \mathrm{O}$ exílio babilônico durou entre 587 e 539 A.E.C. (Bright, 2000, p. 343).
} 
Podemos extrair da Bíblia Hebraica quatro grupos de significados distintos para o termo rûah $(ר)^{4}$ :

- Ar, vento, vendaval, brisa.

- Alento vital, alma, espírito, respiração, fôlego, sopro.

- Expressões do espírito como temperamento humano, consciência, interioridade.

- O espírito divino.

1. Ar, vento, vendaval, brisa.

a. Vento, brisa: "Deus fez soprar um vento sobre a terra, e baixaram as águas" (Gn 8:1)5; "Levá-los-á o vento; um assopro os arrebatará a todos" (Is 57:13); “andava no jardim pela brisa do dia" (Gn 3:8); "um grande e forte vento fendia os montes e despedaçava as penhas" (1 Rs 19:11); "lançou sobre o mar um forte vento" (Jn 1:4); “eis que um vento tempestuoso vinha do norte (Ez 1:4).

b. Vento no sentido de nulidade ou vazio: "Eis que todos são nada; as suas obras são coisa nenhuma; as suas imagens de fundição, vento e vácuo" (Is 41:29).

c. Vento no sentido de direção: "Trarei sobre Elão os quatro ventos dos quatro ângulos do céu e os espalharei na direção de todos estes ventos” (Jr 49:36); "tudo o que restar de ti espalharei a todos os ventos" (Ez 5:10).

d. Vento como tarefa inútil: “Atentei para todas as obras que se fazem debaixo do sol, e eis que tudo era vaidade e correr atrás do vento" (Ec 1:14).

\footnotetext{
${ }^{4}$ Cf. Botterweck \& Ringgren (Theological Dictionary of the Old Testament, 1997, Vol. 13, p. 367-368); Brown, Driver \& Biggs (The New Brown-Driver-Briggs-Gesenius Hebrew and English Lexicon, 1979, p. 924); Jastrow (A Dictionary of the Targumim, The Talmud Babli and Yerushalmi, and the Midrashic Literature, 1996, p. 1458); Koehler \& Baumgartner (Lexicon in Veteris Testamenti Libros, 1985, p. 877); Schökel (Dicionário Bíblico Hebraico-Português, 1997, p. 609-610); Wolff (2007, p. 68). Sekki (1989) faz um estudo das ocorrências de rûah nos pergaminhos de Qumran e divide as ocorrências em: espírito divino; espírito humano; anjo; outros usos: vento, respiração, incerto.

${ }_{5}^{5}$ Similar a "O mar ficou quieto, a tempestade parou, a enchente cessou" (The Epic of Gilgamesh, v. 131, trad. E. A. Speiser, apud Pritchard, 2011, p. 67, tradução nossa).
} 
Segundo o Talmud 6 , o vento foi criado no primeiro dia: “Dez coisas foram criadas no primeiro dia, e são as seguintes: céu e terra, Tohu [caos], Bohu [desolação], luz e escuridão, vento e água, a medida do dia e a medida da noite"7. O vento é uma das dez forças da natureza:

Dez coisas fortes foram criadas no mundo. A rocha é dura, mas o ferro a fende. $\mathrm{O}$ ferro é duro, mas o fogo o amolece. $\mathrm{O}$ fogo é forte, mas a água o apaga. A água é forte, mas as nuvens a suportam. As nuvens são fortes, mas o vento as espalha. $\mathrm{O}$ vento é forte, mas o corpo o aguenta. $\mathrm{O}$ corpo é forte, mas o medo o esmaga. $\mathrm{O}$ medo é forte, mas o vinho o bane. $\mathrm{O}$ vinho é forte, mas o sono resolve. A morte é mais forte do que tudo, e a caridade salva da morte, como está escrito: A caridade livra da morte ${ }^{8}$.

O Livro de Daniel relaciona o conceito de rûaḥ com "direção": "Falou Daniel, e disse: Eu estava olhando, numa visão noturna, e eis que os quatro ventos do céu ${ }^{9}$ agitavam o Mar Grande" (Dn 7:2). O Livro de Enoque possui a mesma ideia: há um vento para cada direção, e os quatro ventos são os pilares do céu ${ }^{10}$. Os Pergaminhos do Mar Morto (Qumran) explicam os quatro ventos das quatro direções:

E, em primeiro lugar,] o vento do leste passa pelo primeiro portão que está no [o leste, e se inclina para o sul; e dele vem destruição, seca, calor e desolação.] E através do segundo portão, [o do meio], sai o vento leste-leste: [chuva e fecundidade e renascimento e orvalho. E através do terceiro portão sai] o lestenorte [vento], que está próximo do vento norte; [frio e seca. E depois deles de três portões que estão na direção do sul dos céus]; sai, em primeiro lugar, através do primeiro portão [um vento sul que está no sul, inclinando-se para o leste: um vento quente.] E através do segundo portão sai um vento sul] que eles chamam de Sul, (trazendo) orvalho [e chuva, bem-estar e renascimento. E pelo terceiro

\footnotetext{
${ }^{6}$ Talmud quer dizer "ensinamento, instrução, estudo" (Jastrow, 1903, p. 1672). É uma das obras fundamentais do judaísmo, sua "Lei Oral", que completa e explica a "Lei Escrita" - o Pentateuco (Hastings, 1909, p. 890). Compõe-se de duas partes: a Mishná e a Guemará, que foram compiladas, respectivamente, por volta dos anos 200 e 500 E.C. Para todas as citações do Talmud será utilizado o software Judaic Classics: The Soncino Talmud. Versão 3.4. New York: Judaica Press, 1990, com tradução nossa.

${ }^{7}$ Talmud Hagiga 12a, grifo nosso.

${ }^{8}$ Talmud Baba Bathra 10a, grifo nosso.

9 "Quatro ventos do céu", em aramaico, ארבע רוחי שמיא.

${ }^{10}$ Livro de Enoque, Seção 1, cáp. 34-36, p. 660-671.
} 
portão sai um vento sudoeste, (trazendo) orvalho e chuva e gafanhotos e destruição]. [E] depois vem um [vento norte. . . e] destruição. ${ }^{11}$

O Talmud corrobora o conceito de rûah como "direção" ou "lado". Alguns exemplos são: "Posso dizer que um homem pode orar voltando-se para qualquer direção que desejar? Portanto, o texto afirma: Em direção a Jerusalém"12, “em um caso, a parede que corre em ângulos retos está de um lado, no outro, em ambos os lados"13; "e o lado norte não é fechado" "14; "os quatro cantos do mundo" $" 15$.

O termo rûah ocorre 14 vezes nos Pergaminhos do Mar Morto (Qumran) como "vento" e 12 vezes como "direção"16.

2. Alento vital, alma, espírito, respiração, fôlego, sopro.

a. O alento em geral, como vida, e sua manifestação na respiração: "medito, e me desfalece o espírito" (S1 77:3); “O meu hálito é intolerável à minha mulher” (Jo 19:17); "se lhes cortas a respiração, morrem e voltam ao seu pó" (S1 104:29) ${ }^{17}$; "Os céus por sua palavra se fizeram, e, pelo sopro de sua boca, o exército deles" (S1 33:6); “com o sopro dos seus lábios matará o ímpio” (Is 11:4); “tendo Sansão bebido, recobrou alento e reviveu" (Jz 15:19); "Não me permite respirar"18 (Jo 9:18).

\footnotetext{
${ }^{11}$ Milik \& Black (1976, p. 284-287 - 4QEnastrc 1 ii 1-10 - En. 76: 3-10, PI. XXVIII, tradução nossa).

12 "יכול יתפלל אדם לכל רוח שירצה? - תלמוד לומר (דניאל ו") (לקבל) [נגד] ירושלם) (Talmud Berachot 31a, grifo nosso). Esse conceito é baseado no costume do profeta Daniel: “...entrou em sua casa, no seu quarto em cima, onde estavam abertas as janelas que davam para o lado de Jerusalém; e três vezes no dia se punha de joelhos e orava...” (Dn 6:10).

13 "כאן מרוח אחת, כאן משתי רוחות" (Talmud Baba Bathra 22b, grifo nosso).

"ורוח צפונית אינה מסובבת" (Talmud Baba Bathra 25b, grifo nosso).

15 "לארבע רוחות העולם מלת (Talmud Pessachim 94a, grifo nosso). "Four corners of the world", segundo a tradução para o inglês do Judaic Classics: The Soncino Talmud; "Four directions of the world", segundo Jastrow (A Dictionary of the Targumim, The Talmud Babli and Yerushalmi, and the Midrashic Literature, 1996, p. 1458).

${ }^{16}$ Sekki (1989, p. 173).

${ }^{17}$ Similar a "Quando você se assenta, eles morrem" (The Hymn to the Aton, trad. J. A. Wilson, apud Pritchard, 2011, p. 327, tradução nossa para o português).

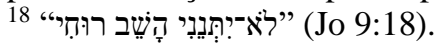


b. Há um jogo de palavras em Ezequiel que envolve espírito, vento e respiração: "Eis que farei entrar o espírito em vós, e vivereis; Porei tendões sobre vós, farei crescer carne sobre vós, sobre vós estenderei pele e porei em vós o espírito, e vivereis. [...] Olhei, e eis que havia tendões sobre eles, e cresceram as carnes, e se estendeu a pele sobre eles; mas não havia neles o espírito; [...] Vem dos quatro ventos, ó espírito, e assopra sobre estes mortos, para que vivam. Profetizei como ele me ordenara, e o espírito entrou neles ${ }^{19}$, e viveram e se puseram em pé, um exército sobremodo numeroso" (Ez 37:5-10).

Para o Talmud, o que define um ser vivo é ter "espírito de vida" (רוּח חַיים ${ }^{20}$.

"Espírito" é a parte imaterial do ser humano ${ }^{21}$, um termo que expressa transcendência das limitações de tempo e espaço ${ }^{22}$. O espírito é, portanto, considerado imortal, em contraste com a “carne", cujas características são: mortalidade, falibilidade, fragilidade, fraqueza e inferioridade ${ }^{23}$. Tudo aquilo que possui carne, não pode ser infalível nem imortal, tem seus dias contados, e depende da generosidade divina para ter vida.

Não lutará comigo o Meu espírito, por causa do homem para sempre, porque também ele é carne; e serão os seus dias cento e vinte anos. (Gn 6:3)

Lembra-se de que eles são carne, vento que passa e já não volta. (S1 78:39)

Pois os egípcios são homens e não deuses; os seus cavalos, carne e não espírito. (Is 31:3).

E formou o Senhor Deus o homem do pó da terra, e soprou-lhe nas narinas o fôlego da vida; e o homem tornou-se alma vivente. (Gn 2:7)

\footnotetext{
19 Similar a "ברוח אשר נתת בי", "no espírito que você me deu” (tradução nossa), presente nos Pergaminhos do Mar Morto (Qumran, 1QH 12:11; 13:19; 16:11; f 3:14), segundo Sekki (1989, p. 87).

20 "[A característica distintiva de] o boi não é como [aquela da] besta destruidora de safras, nem [a característica distintiva de] nenhum destes, que estão vivos, como [o do] fogo, que não está vivo" (Talmud Bava Kama 1:1, grifo

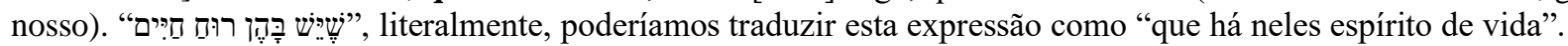

${ }^{21}$ Ferreira (Dicionário Aurélio, 2010, p. 372).

${ }^{22}$ Hastings (1909, p. 874).

23 Cassuto (Bíblia Sifrei Hamikra: Sefer Bereshit, 1965, p. 31); Gunkel (1997, p. 58); Sarna (The JPS Torah Commentary: Genesis, 1989, p. 46).
} 
Se Deus pensasse apenas em si mesmo e para si recolhesse o seu espírito e o seu sopro, toda a carne juntamente expiraria, e o homem voltaria para o pó. (Jo 34:1415)

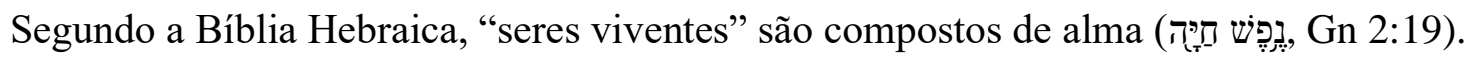

A “alma" é uma entidade espiritual, uma manifestação divina que vitaliza e anima a existência e age como fonte da capacidade do homem de pensar, querer, agir e criar, em contato com a matéria ${ }^{24}$. Os termos "espírito" e "alma" são considerados similares por diversos autores ${ }^{25}$, mas há diferenças entre estes termos.

Naturalmente, a alma é imaterial, e não está somente além da matéria, mas também além do que é considerado espírito, ou seja, está além de tudo o que o intelecto, no seu nível mais alto, pode alcançar e entender ou esclarecer para si mesmo. Portanto, a alma não deve ser concebida como uma certa essência definida, encerrada no corpo, nem como um ponto ou substância imaterial, mas como uma linha contínua de ser espiritual, estendendo-se da fonte geral de todas as almas até além do corpo específico de uma pessoa em particular. A ligação entre o corpo e a alma é como o que acontece no final de um raio de luz, quando um corpo escuro é iluminado. E como a alma não é um ponto único no espaço, ela deve ser encarada não como uma única existência que tem uma qualidade ou caráter, mas como muitas existências, numa variedade de níveis espirituais. Então, para começar, a alma dá ao corpo sua vida e seu ser, esse ser vital que diferencia tudo o que está vivo e é real. Além disso, ela fornece à pessoa individual seu caráter especial e, por conseguinte, fixa a maneira como ela participará da realidade da vida das criaturas do mundo ${ }^{26}$.

A alma diferencia-se do espírito por ser um termo mais abrangente. O espírito, por sua vez, é um dos níveis da alma, que são os seguintes ${ }^{27}$ :

\footnotetext{
${ }^{24}$ Steinsaltz (1992, p. 54-56).

${ }^{25}$ A "alma" é o "espírito, pessoa, indivíduo, vida", enquanto o espírito é "alma, vento, brisa, ar, tendência, fantasma, ponto cardeal, lado" (Berezin, 2003, p. 456, 597); a "alma" é definida como o "princípio da vida" ou um "princípio espiritual do homem concebido como separável do corpo e imortal, sede dos afetos, sentimentos e paixões", enquanto o "espírito" é definido como "a parte imaterial do ser humano" (Ferreira, Dicionário Aurélio, 2010, p. 111, 372).

${ }^{26}$ Steinsaltz (1992, p. 53-54).

${ }^{27}$ Cf. "Por cinco nomes é a alma chamada: nefesh, ruach, neshamah, chayah (vivente), yechidah (única)" (Midrash Bereshit Raba 14:9, disponível em: <https://www.sefaria.org/Bereishit_Rabbah.14.9?lang=bi>, acesso em: 28/10/21, tradução nossa); Steinsaltz (1992, cap. I e III); Zukerwar (1997, cap. 2 e 9).
} 
- Nefesh ("נפש", alma inferior): relacionada aos instintos, ligada ao corpo físico, localiza-se no mundo da ação. Subdivide-se em "alma animal" e "alma divina". A alma animal é o nível mais primário, que vitaliza o corpo, anima a existência em termos de força de vida, movimento e propagação da espécie; e depois, em outro nível, age como fonte da capacidade do homem para pensar, imaginar, sonhar. É chamada alma animal por ser paralela às almas de outras criaturas vivas, não estando ligada apenas a necessidades físicas, mas também é a fonte dos aspectos ou qualidades peculiares a cada um como pessoa. A alma divina, por outro lado, está diretamente ligada à sua essência divina, é a primeira faísca de consciência além da espécie zoológica. Existe em cada ser individual, escondida e encoberta como uma faísca de uma percepção ou aspiração superior. O mundo da ação é o mundo em que vivemos, onde se encontram os reinos mineral, vegetal, animal e o homem. Engloba o mundo da natureza física, onde a lei natural prevalece, e o mundo da ação espiritual. O homem é a criatura que participa de ambos, estando subordinado às leis físicas, químicas e biológicas da natureza e, ao mesmo tempo, do ponto de vista da sua consciência, pertence ao mundo espiritual das ideias. O pensamento, por mais que seja abstrato ou separado da realidade, ainda pertence ao mundo da ação. Aqui, existe o espaço físico, necessário para a existência das coisas. Tudo depende do espaço físico para se deslocar e funcionar. O tempo é medido pelo movimento de corpos celestes (anos, meses, semanas, dias).

- Ruah ("רוח", espírito): relacionado às emoções, ligado ao coração, corresponde ao nível de um anjo no mundo da formação, que pode ser considerado um mundo de sentimento ou emoção. Os seres vivos que funcionam neste mundo são os anjos, que são manifestações conscientes de impulsos particulares. Um anjo é uma realidade espiritual com conteúdo, qualidades e caráter singular. Sua qualidade substancial pode ser um impulso ou uma inclinação (exemplos: uma inclinação para o amor ou um ataque de medo). Um anjo é totalmente a manifestação de uma essência emocional única. É um ser completo e íntegro, consciente de si mesmo e do que o rodeia, capaz de agir dentro da estrutura de seu mundo. A palavra anjo em hebraico (מלאך) significa mensageiro, e o anjo é um emissário entre mundos. Porém, diferentemente do homem, não possui contradições e não distingue entre 
o bem e o mal. O anjo é eternamente o mesmo, estático, imutável. Pensamentos, atos e experiências do mundo da ação podem dar origem à anjos de tipos diferentes. Cada anjo, tendo um caráter bem definido, pode efetuar somente uma missão, porque a essência de um anjo está além dos aspectos múltiplos do homem. A mansão é o elemento, nos mundos "superiores", análogo ao que chamamos de espaço, no nosso mundo. Uma espécie de "lugar" abstrato. O tempo também tem um valor diferente. Quanto mais espiritual o mundo, mais abstrato e menos representativo se torna o conceito de tempo.

- Neshamah ("נשמה", alma superior): relacionada ao pensamento (intelecto), ligada ao cérebro, corresponde ao nível dos serafins no mundo da criação. O mundo da criação é um mundo de mente pura, do poder e a capacidade de captar coisas com uma compreensão autêntica, interior. É o mundo da mente que registra e absorve o conhecimento. É também conhecido como o "mundo do trono" (da visão de Ezequiel do Divino Trono da Glória ${ }^{28}$ ). As criaturas deste mundo são os "serafins", anjos superiores, que também têm essências abstratas singulares, não passíveis de mudanças, porém de inteligência pura. São anjos que manifestam os níveis superiores da mente. São também mensageiros, como os outros anjos.

- Chaya ("חיה"): relacionada à vontade, transcende ao corpo, corresponde à ação das forças das sefirot ${ }^{29}$ no mundo da emanação. O mundo da emanação, num certo sentido, não é um

\footnotetext{
28 "E sobre o firmamento, que estava por cima das suas cabeças, havia uma semelhança de trono, como a aparência duma safira; e sobre a semelhança do trono havia como que a semelhança dum homem, no alto, sobre ele. E vi como o brilho de âmbar, como o aspecto do fogo pelo interior dele ao redor desde a semelhança dos seus lombos, e daí para cima; e, desde a semelhança dos seus lombos, e daí para baixo, vi como a semelhança de fogo, e havia um resplendor ao redor dele. Como o aspecto do arco que aparece na nuvem no dia da chuva, assim era o aspecto do resplendor em redor. Este era o aspecto da semelhança da glória do Senhor; e, vendo isso, caí com o rosto em terra, e ouvi uma voz de quem falava" (Ez 1:26-28).

${ }^{29}$ Sefirot são dez números arquetípicos considerados os poderes fundamentais de toda existência, segundo Scholem (1978, p. 121). O misticismo judaico é representado por duas obras principais: em primeiro lugar, pela obra Sefer Ietsirá, o "Livro da Criação", obra esotérica mencionada pelo Talmud (Sanhedrin 65b; 67b), provavelmente do século III E.C. (ibid., p. 205), que descreve como o cosmo foi construído a partir das vinte e duas letras do alfabeto hebraico (ibid., p. 201). Essa obra possuía o título adicional: "Alfabeto de Nosso Pai Abraão" (ibid., p. 203). Segundo Jastrow (1903, p. 589), o nome do livro significa "formação, criação ou natureza". Em segundo lugar, o livro Zohar, o "Livro do Esplendor" (Scholem, 1978, p. 7), obra teosófica cabalística escrita por Moisés de Leon de forma pseudoepigráfica, como sendo uma coletânea de diálogos entre Rabi Simão Bar Iocai e seus discípulos, no século II E.C. (ibid., p. 71). Segundo Jastrow (1903, p. 382), o nome do livro significa "brilhar, florescer, emitir luz, reluzir". O conceito das dez sefirot encontra-se no primeiro capítulo do livro Ietsirá (Kaplan, Sêfer Ietsirá: O Livro da Criação, 2002, 1:2, 4, 6, 7, 8), enquanto no livro Zohar há muitas ocorrências desses termos.
} 
mundo real - não há ocultamento de nenhuma essência, não há individualidade separada, é composto por divinidade.

- Yehidah ("יחידה"): sede do prazer, transcende ao corpo, corresponde ao ponto de contato entre a alma e a própria essência divina.

Tabela 1. Partes da alma

\begin{tabular}{|c|c|c|c|c|}
\hline Parte da Alma & $\begin{array}{l}\text { Relação com a } \\
\text { Pessoa }\end{array}$ & $\begin{array}{c}\text { Relação com parte } \\
\text { do corpo }\end{array}$ & $\begin{array}{l}\text { Localização } \\
\text { (mundos) }\end{array}$ & Observação \\
\hline Nefesh & Corpo (Instinto) & Fígado, sangue & $\begin{array}{l}\text { Ação } \\
\text { (homem) }\end{array}$ & $\begin{array}{l}\text { Alma vitativa, faz } \\
\text { funcionar os órgãos }\end{array}$ \\
\hline Ruah & Emoções & Coração & $\begin{array}{l}\text { Formação } \\
\text { (anjos) }\end{array}$ & $\begin{array}{l}\text { Fica fora de ordem } \\
\text { quando a pessoa } \\
\text { dorme }\end{array}$ \\
\hline Neshama & Intelecto & Cérebro & $\begin{array}{l}\text { Criação } \\
\text { (serafins) }\end{array}$ & $\begin{array}{l}\text { Fica fora de ordem } \\
\text { quando a pessoa } \\
\text { dorme }\end{array}$ \\
\hline Haia & Vontade & $\begin{array}{l}\text { Transcende ao } \\
\text { corpo }\end{array}$ & Emanação & $\begin{array}{l}\text { Transcende ao } \\
\text { corpo }\end{array}$ \\
\hline Yehida & Prazer (Plenitude) & $\begin{array}{l}\text { Transcende ao } \\
\text { corpo }\end{array}$ & Emanação & $\begin{array}{l}\text { Transcende ao } \\
\text { corpo }\end{array}$ \\
\hline
\end{tabular}

O termo rûah também está presente nos Pergaminhos do Mar Morto (Qumran) 5 vezes como "respiração" ou "fôlego" 30 .

3. Expressões do espírito como temperamento humano, consciência, interioridade.

a. Qualidades: “Toma Josué, filho de Nun, homem em quem há o Espírito” (Nm 27:18); "Então o mesmo Daniel sobrepujava a estes presidentes e aos sátrapas; porque nele havia um espírito excelente" (Dn 6:3).

b. Ânimo ou desânimo: "reanimou-lhe o espírito" (Gn 45:27); "O espírito firme sustém o homem na sua doença, mas o espírito abatido, quem o pode suportar?”

${ }^{30}$ Sekki (1989, p. 179). 
(Pr 18:14); “...mas eles não atenderam a Moisés, por causa da ânsia de espírito e da dura escravidão"31 (Ex 6:9).

c. Cólera: "Não te apresses em irar-te" "32 (Ec 7:9); "porque dos tiranos o bufo é como a tempestade contra o muro",33 (Is 25:4); "O insensato expande toda a sua ira" $^{\circ 4}(\operatorname{Pr} 29: 11)$.

d. Angústia: "falarei na angústia do meu espírito"35 (Jo 7:11).

e. Coração, sentimento: "eis que derramarei copiosamente para vós outros o meu espírito e vos farei saber as minhas palavras" (Pr 1:23).

f. Consciência: “Todos os caminhos do homem são puros aos seus olhos, mas o SENHOR pesa o espírito" (Pr 16:2).

g. Dominar a paixão: "Melhor é o longânimo do que o herói da guerra, e o que domina o seu espírito, do que o que toma uma cidade" (Pr 16:32).

h. Animosidade: "Pelo que o Deus de Israel suscitou o espírito de Pul, rei da Assíria, e o espírito de Tiglate-Pileser, rei da Assíria, que os levou cativos" (1 Cr 5:26).

i. Agitação: "De manhã, achando-se ele de espírito perturbado...” (Gn 41:8).

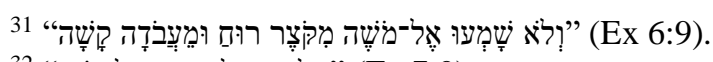

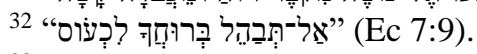

33 "(Is 25:4).

34 "(Pr 29:11).

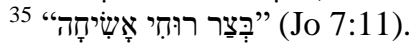


j. Paciência: "Não tenho motivo de me impacientar?"36 (Jo 21:4); "melhor é o paciente do que o arrogante"37 (Ec 7:8).

k. Presunção: "A soberba precede a ruína, e a altivez do espírito, a queda"38 (Pr $16: 18)$.

1. Adjetivo qualificado: "Acharíamos, porventura, homem como este, em quem há o Espírito de Deus?" (Gn 41:38); "e o enchi do Espírito de Deus, de habilidade, de inteligência e de conhecimento, em todo artifício" (Ex 31:3); "porque um espírito de prostituição os enganou" (Os 4:12); "Dar-vos-ei coração novo e porei dentro de vós espírito novo" (Ez 36:26) 39; “e também removerei da terra os profetas e o espírito imundo" (Zc 13:2); "será o espírito de justiça para o que se assenta a julgar" (Is 28:6); "e veio todo homem cujo coração o moveu e cujo espírito o impeliu" (Ex 35:21); "Que é isso que tens assim desgostoso o teu espírito e não comes pão?” (1 Rs 21:5).

O Talmud também se utiliza do termo rûah para denotar o temperamento ou as características humanas: "E mais preciosa é uma hora de tranquilidade do mundo vindouro, do que toda a vida neste mundo" 40 ; "Seja de espírito humilde diante de todos os homens" "1.; "e seja humilde e paciente" 42 .

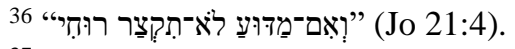

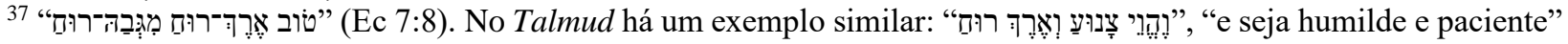
(Avot 6:1). Nos Pergaminhos do Mar Morto (Qumran) há também uma expressão semelhante: "ארוכי רוחיר", "gentil, paciente" (1 QM 6:12, Sekki, 1989, p. 179-180).

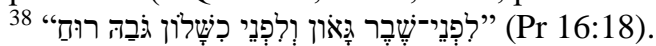

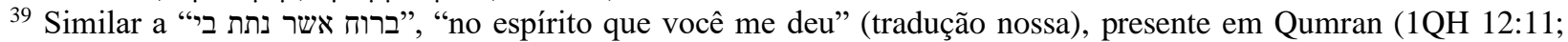
13:19; 16:11; f 3:14), segundo Sekki (1989, p. 87).

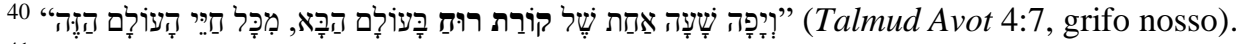

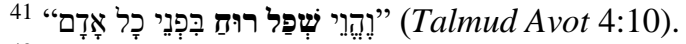

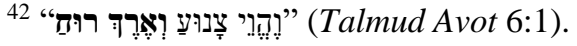


Portanto, rûah, ou seja, o "espírito" ou "vento", é comparado ao temperamento humano. É supostamente natural comparar o vento invisível com a disposição ou situação mental do ser humano, assim como os efeitos visíveis produzidos pelo vento com a ação humana ${ }^{43}$.

4. O espírito divino.

a. "A terra, porém, estava sem forma e vazia; havia trevas sobre a face do abismo, e o Espírito de Deus pairava por sobre as águas” (Gn 1:2) ${ }^{44}$; “Quem guiou o Espírito do SENHOR?” (Is 40:13); “o Espírito do SENHOR lhes deu descanso” (Is 63:14); “ele me levou pelo Espírito do SENHOR” (Ez 37:1); “guie-me o teu bom Espírito por terreno plano” (S1 143:10); “O Espírito de Deus me fez, e o sopro do Todo-Poderoso me dá vida" (Jo 33:4); "Repousará sobre ele o Espírito do SENHOR, o Espírito de sabedoria e de entendimento, o Espírito de conselho e de fortaleza, o Espírito de conhecimento e de temor do SENHOR” (Is 11:2$3)$.

b. Espírito divino como dom profético ao homem: "tirarei do Espírito que está sobre ti e o porei sobre eles [...] Então, o SENHOR desceu na nuvem e lhe falou; e, tirando do Espírito que estava sobre ele, o pôs sobre aqueles setenta anciãos; quando o Espírito repousou sobre eles, profetizaram; mas, depois, nunca mais” (Nm 11:17, 25); "No entanto, os aturaste por muitos anos e testemunhaste contra eles pelo teu Espírito, por intermédio dos teus profetas; porém eles não deram ouvidos; pelo que os entregaste nas mãos dos povos de outras terras" (Ne 9:30); "Repousará sobre ele o Espírito do SENHOR" (Is 11:2); “O Espírito do SENHOR se apossará de ti, e profetizarás com eles e tu serás mudado em outro homem" (1 Sm 10:6).

\footnotetext{
${ }^{43}$ Cheyne \& Black (Encyclopaedia Biblica, 1903, Vol. 4, p. 4751).

${ }^{44}$ Outra ocorrência de rûah relacionada à Criação: "Envias o teu Espírito, eles são criados, e, assim, renovas a face da terra" (S1 104:30), onde há similaridades com: "The world came into being by thy hand, According as thou hast made them. When thou hast risen their life" (The Hymn to the Aton, trad. J. A. Wilson, apud Pritchard, 2011, p. 327).
} 
Nos Pergaminhos do Mart Morto, há 35 ocorrências do termo rûah referindo-se ao espírito divino, em oposição ao espírito do homem, que possui 97 ocorrências. Os pergaminhos tendem a descrever o homem não apenas como possuidor de um espírito, mas como sendo um. Os pergaminhos também apresentam o termo rûaḥ referindo-se a seres celestiais 58 vezes, na maioria dos casos no plural masculino acompanhado de outro substantivo ou adjunto ${ }^{45}$.

O espírito divino como dom profético está presente no Talmud: "[o livro de] Ester foi composto sob a inspiração do espírito profético"46; "Depois que os profetas posteriores Ageu, Zacarias e Malaquias morreram, o espírito profético partiu de Israel" ${ }^{\text {. }}$.

São poucos os homens que atingem o privilegiado nível profético, agraciados com o espírito divino. Há uma expressão rabínica que explicita como é possível alcançar este dom:

O estudo da Torá leva ao cuidado no cumprimento dos mandamentos. O cuidado no cumprimento dos mandamentos leva à diligência em sua observância. A diligência leva à limpeza da alma. A limpeza da alma conduz à abstenção de todo mal. A abstenção do mal leva à pureza e à eliminação de todos os desejos vis. Pureza leva à piedade. A piedade leva à humildade. A humildade leva ao medo do pecado. O medo do pecado leva à santidade. Santidade leva ao espírito

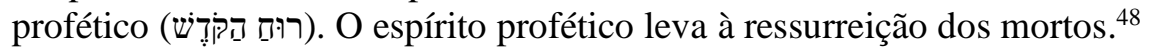

Entende-se que apenas homens virtuosos, com uma forte e sincera fé, estariam aptos a sentir esta influência divina, galgando tantos degraus, cada um caracterizando um nível de comportamento a ser atingido com trabalho e esforço.

E o local mais frequente e constante para que o Espírito Divino se manifeste é o local do Templo de Jerusalém, localizado no território da tribo de Benjamin ${ }^{49}$. As prováveis explicações

\footnotetext{
45 Sekki (1989, p. 71, 95, 99, 145-146). Exemplo: “"כל רוחי אמת”, “todos espíritos da verdade” (1QM 13:10, tradução nossa).

46 "אסתר לאו ברוח הקודש נאמרה?" (Talmud Meguila 7a, grifo nosso).

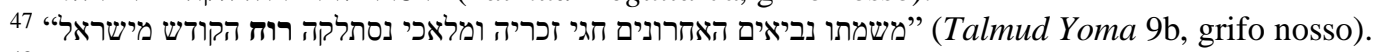

48 Talmud Avoda Zara 20b; Mishná Sotá 9:15, disponível em: <https://www.sefaria.org/Mishnah_Sotah. 9.15?lang=bi>, acesso em: 30/11/2021.

49 Midrash Bamidbar Raba 14:8-9, disponível em: <https://www.sefaria.org/Bamidbar_Rabbah.14.8?lang=bi>, acesso em: 30/11/2021. Veja mapa do território de cada uma das tribos de Israel e outras informações sobre o assunto em: The Twelve Tribes of Israel, em: World History Encyclopedia, disponível em: <https://www.worldhistory.org/article/1822/the-twelve-tribes-of-israel/>, acesso em: 30/11/2021.
} 
para esta localização podem ser: Benjamin não participou da venda de José junto com seus outros irmãos ${ }^{50}$; Benjamin é o único dos filhos de Jacob ou Israel que não nasceu em Harã, mas sim, na terra de Canaã, futuramente chamada de Israel $^{51}$. Há também uma parábola midráshica a respeito de dois irmãos que se ajudavam mutuamente, que ilustra a bondade dos moradores do local ${ }^{52}$.

Algumas outras formas da mesma raiz de rûah podem significar "tornar-se espaçoso" ou "sentir-se aliviado", além da palavra rêah, "cheiro, odor, aroma"53.

O termo rûah pode significar, simultaneamente, "respiração, vento ou espírito" 54 , e está, em diversas ocasiões, relacionado à criação: “o Espírito de Deus pairava por sobre as águas” (Gn 1:2), "o espírito entrou neles, e viveram e se puseram em pé” (Ez 37:10), "Os céus por sua palavra se fizeram, e, pelo sopro de sua boca, o exército deles" (S1 33:6), "Envias o teu Espírito, eles são criados, e, assim, renovas a face da terra” (S1 104:30), "O Espírito de Deus me fez, e o sopro do Todo-Poderoso me dá vida" (Jo 33:4). "Sopro" e "respiração" simbolizam "espírito" e "vida". Alguns autores, consequentemente, traduzem rûaḥ como "espírito criativo" ou "energia vital" 55 .

A relação entre "vento" e "espírito" com a criação também é exemplificada por diversas mitologias. Segundo a mitologia egípcia, Shu é o deus do ar, com domínio sobre os quatro ventos e, ao mesmo tempo, o princípio vital ${ }^{56}$. O deus Osíris é aclamado como o doador universal da vida: "Você sopra ar de sua garganta para as narinas de seres humanos" 57 . Ar e vento são manifestações cósmicas da vida, o sopro dos deuses que concede vida aos mortais.

\footnotetext{
${ }^{50}$ José nasceu no ano de 2199 do calendário judaico, enquanto Benjamin nasceu no ano de 2208. José foi vendido pelos irmãos no ano de 2216 (Kantor, 2005, p. 62-63). Portanto, José foi vendido aos 17 anos de idade, enquanto Benjamin tinha apenas 8 anos na ocasião.

${ }^{51} \mathrm{Gn}$ 29-30, 35:18.

52 "Entre as grandes realizações de Salomão, o primeiro lugar deve ser atribuído ao magnífico Templo construído por ele. Ele ficou em dúvida há muito tempo sobre onde construí-lo. Uma voz celestial instruiu-o a ir ao Monte Sião à noite, a um campo de propriedade de dois irmãos em conjunto. Um dos irmãos era solteiro e pobre, o outro era abençoado com riquezas e uma grande família com filhos. Era a época da colheita. Sob o manto da noite, o irmão pobre não parava de aumentar a pilha de grãos do outro, pois, embora fosse pobre, achava que seu irmão precisava de mais por causa de sua grande família. O rico irmão, da mesma forma clandestina, aumentou o estoque do irmão pobre, pensando que embora tivesse uma família para sustentar, o outro não tinha meios. Este campo, concluiu Salomão, que suscitou uma manifestação tão notável de amor fraternal, era o melhor local para o Templo, e ele o comprou" (GINZBERG, Vol. 4, 57).

${ }^{53}$ Koehler \& Baumgartner (Lexicon in Veteris Testamenti Libros, 1985, p. 877).

${ }^{54}$ Brown, Driver \& Biggs (The New Brown-Driver-Briggs-Gesenius Hebrew and English Lexicon, 1979, p. 924).

${ }^{55}$ Frahm (2013, p. 113).

${ }^{56}$ Botterweck \& Ringgren (Theological Dictionary of the Old Testament, 1997, Vol. 13, p. 368-372).

${ }^{57}$ Botterweck \& Ringgren (Theological Dictionary of the Old Testament, 1997, Vol. 13, p. 371, tradução nossa). Comparando com a Bíblia Hebraica: "soprou nas narinas o fôlego de vida" (Gn 2:7).
} 
Os fenícios, por sua vez, acreditavam que o ar e o vento foram elementos fundamentais da criação do mundo. Na mitologia fenícia, os ventos precedem a divindade, ao contrário da Bíblia Hebraica (רוח אלהים, “Espírito [ou "vento"] de Deus”, Gn 1:2).

[...] I found the mythology of the Phoenicians, according to Mochos, to be as such: at the beginning there was Aether and Air, two principles themselves, from whom Oulomos ${ }^{58}$ was born, the intelligible god, himself, I think, the peak of the intelligible. From him, they say, mating with himself, was born first Chousoron ${ }^{59}$ the opener, then an egg; the latter, I think, they call the intelligible intellect, and the opener Chousoron they call the intelligible force, as it was the first to differentiate undifferentiated nature. Unless after these two principles the highest is the one Wind, while the middle are the two winds Lips and Notos - for they make even these somehow precede Oulomos. As for Oulomos, he would be the intelligible intellect himself, and the opener Chousoros would be the first order after the intelligible, and the egg would be the sky; for they say that Ouranos (Sky) and Ge (Earth) were born from the egg as it broke in two, each one from one of the two halves ${ }^{60}$.

Nos textos ugaríticos, rḥ pode representar rûaḥ ou rêaḥ, "cheiro, odor, aroma". Em acádio, o termo equivalente é šāru, "vento, tempestade, sopro (do deus)", como também "sopro de vida, bênção", similar ao termo $s^{e e} \bar{a} r a ̂$, que também significa "vento", porém mais violento, intenso ou destrutivo, como um furacão, redemoinho ou tempestade: "persegue-os com a tua tempestade"61 (S1 83:15); ou a combinação dos termos rûah e $s^{e e} \bar{a} r a ̂$ : "um vento tempestuoso vinha do Norte"62 (Ez 1:4). No mito acádio Enuma Elish, Marduk utiliza-se dos ventos como armas na batalha contra Tiamat:

Marduk is king! (28) [...]

Go and cut off the life of Tiamat! (31) [...]

\footnotetext{
${ }^{58}$ Adaptação para o grego do termo fenício ulam (עלם), conforme o termo hebraico olam (עולם), que significa "para sempre" ou "eternamente" (Brown, Driver \& Biggs, The New Brown-Driver-Briggs-Gesenius Hebrew and English Lexicon, 1979, p. 762-763; Dicionário Hebraico Even-Shoshan, 2003, Vol. 3, p. 847; Harris, Archer \& Waltke, Dicionário Internacional de Teologia do Antigo Testamento, 1998, p. 1126; Koehler \& Baumgartner, Lexicon in Veteris Testamenti Libros, 1985, p. 588; Schökel, Dicionário Bíblico Hebraico-Português, 1997, p. 483). Parece estar se referindo ao Deus Eterno (אל עולם, Gn 21:33), segundo Darshan (2019, p. 60).

${ }^{59}$ O deus-artesão ugarítico (Darshan, 2019, p. 60).

${ }^{60}$ Kaldellis, A \& López-Ruiz. Philon (790), in: Worthington, I (ed.). Brill's New Jacoby, 2009, disponível em: <http://dx.doi.org/10.1163/1873-5363_bnj_a790>, acesso em: 01/07/2018, em: Darshan (2019, p. 60).

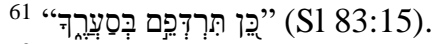

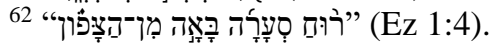


He then made a net to enfold Tiamat therein.

The four winds he stationed that nothing of her might escape,

The South Wind, the North Wind, the East Wind, the West Wind.

Close to his side he held the net, the gift of his father, Anu.

He brought forth Imhullu "the Evil Wind", the Whirlwind, the Hurricane,

The Fourfold Wind, the Sevenfold Wind, the Cyclone, the Matchless Wind;

Then he sent forth the winds he had brought forth, the seven of them. $(41-47)^{63}$

Segundo a Bíblia Hebraica, os ventos servem a Deus, são seus agentes: “Tu estendes o céu como uma cortina, pões nas águas o vigamento da tua morada, tomas as nuvens por teu carro e voas nas asas do vento. Fazes a teus anjos ventos e a teus ministros, labaredas de fogo" (S1 104:24); “...e o Eterno dirigiu um vento oriental à terra, todo aquele dia e toda a noite” (Ex 10:13); "E mandou o Eterno um vento do poente, muito forte...” (ibid., 10:19). O vento também está relacionado com a separação entre a abóbada celeste superior e a inferior: "Haja firmamento no meio das águas e separação entre águas e águas” (Gn 1:6), como também entre a terra e as águas: “as águas ficaram acima das montanhas; à tua repreensão, fugiram, à voz do teu trovão, bateram em retirada" (S1 104:6-7) ${ }^{64}$.

As afirmações confirmam que Deus é a fonte de rûah̆, e a vida de cada um pressupõe a contínua presença do "espírito divino": "Não lutará comigo o Meu espírito, por causa do homem para sempre, porque também ele é carne; e serão os seus dias cento e vinte anos” (Gn 6:3); “O Espírito de Deus me fez, e o sopro do Todo-Poderoso me dá vida" (Jo 33:4); "Envias o teu Espírito, eles são criados, e, assim, renovas a face da terra" (S1 104:30) ${ }^{65}$; “e o pó volte à terra, como o era, e o espírito volte a Deus, que o deu" (Ec 12:7).

Assim, a vida humana é sustentada e renovada pelo divino rûaḥ.

\footnotetext{
${ }^{63}$ The Creation Epic - Enuma Elish, Trad. E. A. Speiser, apud Pritchard (2011, p. 29).

${ }^{64}$ Botterweck \& Ringgren (Theological Dictionary of the Old Testament, 1997, Vol. 13, p. 385). "As águas ficaram acima das montanhas" (S1 104:6), similar a "Pois tu colocaste um Nilo no céu, para que desça para eles e faça ondas sobre a montanhas" (The Hymn to the Aton, trad. J. A. Wilson, apud Pritchard, 2011, p. 327, tradução nossa para o português).

65 Similar a "O mundo nasceu pela tua mão, conforme tu os fizeste. Quando tu elevaste a vida deles" (The Hymn to the Aton, trad. J. A. Wilson, apud Pritchard, 2011, p. 327, tradução nossa para o português).
} 


\section{Bibliografia}

BEREZZIN, Jaffa Rivka. Dicionário Hebraico-Português. São Paulo: Editora Universitária de São Paulo, 1995.

BÍBLIA. Hebraico. Sifrei Hamikra: Sefer Bereshit. Comentários de M. D. Cassuto e A. S. Hartom. Tel Aviv: Iavne, 1965, pp. 30-31.

BÍBLIA. Inglês. The Stone Edition Tanach. Ed. R. Nosson Scherman. New York: Mesorah Publications Ltd., 1996.

BÍBLIA. Português. Almeida Revista e Atualizada. Trad. João Ferreira de Almeida. Rio de Janeiro: Sociedades Bíblica do Brasil, 2017.

BÍBLIA. Português. Bíblia de Jerusalém. 2a impressão. São Paulo: Paulus, 2003.

BÍBLIA. Português. Torá: A Lei de Moisés. Trad. Meir Matzliah Melamed. São Paulo, Sefer, 2001.

BOTTERWECK, G. Johannes; RINGGREN, Helmer [ed.]. Theological Dictionary of the Old Testament. Grand Rapids (MI): William B. Eerdmans Publishing Company, 1997.

BRIGHT, John. A History of Israel. Louisville (KY): Westminster John Knox Press, 2000.

BROWN, Francis; DRIVER, S. R.; BRIGGS, Charles A. The New Brown-Driver-Briggs-Gesenius Hebrew and English Lexicon. Peabody (MA): Hendrickson Publishers, 1979.

CHEYNE, T. K.; BLACK, J. S. Encyclopaedia Biblica. Vol. 4. New York: The Macmillan Company, 1903. 
DARSHAN, Guy. Ruah 'Elohim in Genesis 1:2 in Light of Phoenician Cosmogonies: $A$ Tradition's History, em: Journal of Northwest Semitic Languages 45/2 (2019), pp. 51-78, disponível em: <http://academic.sun.ac.za/jnsl>, acesso em: 27/10/2021.

EVEN-SHOSHAN, Avraham. Milon Even-Shoshan. (Dicionário Hebraico). Hamilon Hechadash, 2003.

FERREIRA, Aurélio Buarque de Holanda. Miniaurélio: o minidicionário da língua portuguesa. $7^{\text {a }}$ Ed. Curitiba: Positivo, 2010.

FRAHM, Eckart. Creation and the Divine Spirit in Babel and Bible: Reflections on mummu in Enüma eliš I 4 and ruaḥ in Genesis 1:2, em VANDERHOOFT, David S.; WINITZER, Abraham. [ed.] Literature as Politics, Politics as Literature: Essays on the Ancient Near East in Honor of Peter Machinist. Winona Lake, Indiana: Eisenbrauns, 2013, p. 97-116, disponível em: <https://www.academia.edu/5594517>, acesso em: 27/10/2021.

GINZBERG, Louis. The Legends of the Jews. Vol. 4. Trad. Henrietta Szold. The Project Gutenberg, 1998.

GUNKEL, Herman. Genesis. Macon (Georgia): Mercer University Press, 1997.

HARRIS, R. Laird; ARCHER Jr., Gleason L.; WALTKE, Bruce K. [org.]. Dicionário Internacional de Teologia do Antigo Testamento. Trad. Márcio Loureiro Redondo; Luiz Alberto T. Sayão; Carlos Osvaldo C. Pinto. São Paulo: Vida Nova, 1998.

HASTINGS, James. Dictionary of the Bible. New York: Charles Scribner's Sons, 1909.

JASTROW, Marcus [ed.]. A Dictionary of the Targumim, The Talmud Babli and Yerushalmi, and the Midrashic Literature. New York: The Judaica Press, 1996.

KANTOR, R. M. Chronological Index of Jewish History. New York: Zichron Press, 2005. 
KAPLAN, Aryeh. Sêfer Ietsirá: O Livro da Criação. Trad. Erwin Von-Rommel Vianna Pamplona. São Paulo: Sefer, 2002.

KOEHLER, Ludwig; BAUMGARTNER, Walter [ed.]. Lexicon in Veteris Testamenti Libros. Leiden: E. J. Brill, 1985.

MILIK, J. T.; BLACK, M. The Books of Enoch: Aramaic Fragments of Qumran Cave 4. Oxford: Clarendon Press, 1976, disponível em: <https://ia801600.us.archive.org/27/items/MILIK EnochInAramaicQumranCave4/MILIK_Enoch-in-Aramaic-Qumran-Cave-4.pdf>, acesso em: 26/12/2021.

PRITCHARD, James B. [ed.]. The Ancient Near East: An Anthology of Texts \& Pictures. Princeton (NJ): Princeton University Press, 2011.

SARNA, Nahum M. [ed.] The JPS Torah Commentary: Genesis. Philadelphia: The Jewish Publication Society, 1989.

SCHÖKEL, Luis Alonso. Dicionário Bíblico Hebraico-Português. Trad. Ivo Storniolo; José Bortolini. São Paulo: Paulus, 1997.

SCHOLEM, Gershom G. A Cabala e seu Simbolismo. São Paulo: Perspectiva, 1978.

SEKKI, Arthur Everett. The meaning of ruach at Qumran. Wisconsin (Madison): Society of Biblical Literature, 1989.

SOFTWARE Bible Hub, Glassport (PA): Online Parallel Bible Project, 2013, disponível em: $<$ biblos.com>.

SOFTWARE Judaic Classics: The Soncino Talmud. Versão 3.4. New York: Judaica Press, 1990. 
STEINSALTZ, A. E. Y. A Rosa de Treze Pétalas; São Paulo, Maayanot, 1992.

THE Book of Enoch. Trad. R. H. Charles. Scotts Valley (CA): IAP, 2009, versão Kindle.

ZUKERWAR, C. D. As 3 Dimensões da Kabalá; São Paulo, Sefer, 1997. 